\title{
Introduction
}

Historique de la néphrite albumineuse, the 'History of albuminous nephritis', from volume 2 of Dr. Pierre-François Olive Rayer's Traité des maladies des reins, is singularly the most important historical account and main reference source on the subject of nephritis of the nineteenth century. It is significant that both authors of the present volume independently undertook the translation into English of this section of Rayer's book while preparing major manuscripts on the history of renal medicine.

The 'History of albuminous nephritis' represents only a small part of Rayer's work on the kidney. Three years after the publication in 1827 of Dr. Richard Bright's seminal work on nephritis, Reports of medical cases, Rayer set aside his distinguished career in dermatology and concentrated his energies on studies of the kidney. Between 1839 and 1841 he completed a three-volume treatise that was the most comprehensive work then published in both nephrology and urology and the first of its kind in these specialties. It was a formidable performance and down the years few renal textbooks have compared with its thoroughness. Some indication of the wide range of renal conditions described can be gleaned from a perusal of the title page of volume 2 (reproduced as a frontispiece to this book) and from the summary of the contents given in Appendix 1 (page 94). His textbook heralded the age of specialization in medicine; Rayer was one of its earliest proponents. It is sad that his book was so little known in Britain and one can only regret that his physician colleagues in Britain failed to translate the treatise into English. In fact, this would have been a rare event in the nineteenth century, although it is interesting that Rayer's Traité théorique et pratique des maladies de la peau (published in 1826-7) was translated into English by Dr. W. B. Dickinson and into Italian by Professor Giambattista Fantonetti. Perhaps some of Rayer's more chauvinistic English contemporaries were reluctant to recognize the towering intellects of some of the multi-talented physicians of the French school of medicine and to accord them the merit that was their due. However, we do know that many of the more enlightened physicians from Britain, including Bright, had visited Paris to learn the art of auscultation from René-Théophile-Hyacinthe Laënnec (1781-1826). It seems likely that Bright also met Rayer at that time; Rayer leaves no doubt in his writings that Bright was his main inspiration.

Bright's researches concentrated mainly on nephritis, calculi and renal cysts; Rayer, however, studied the kidney and urine in great depth, both in health and disease. He recorded almost every known pathology of the kidney, not only including nephritis, but also pyelitis, pyelonephritis, hydronephrosis, traumas, haemorrhages of the kidney, cysts, hypertrophy, atrophy and congenital malformations. He even included some comparative anatomy, citing examples of veterinary renal morphology.

Rayer was determined to tackle renal disease in the same systematic way that he had dermatology, producing a comprehensive textbook, complemented by an atlas illustrating the most important pathologies. Volume 1 of the treatise comprises an introductory discourse on diseases of the kidney and their classification. It includes remarks on the gross anatomy of the kidney, describes the appearance of the cut surface examined using a hand 


\section{The History of Albuminous Nephritis}

lens, and gives advice on post-mortem changes and necropsy techniques. There are eight tables on the size and weight of kidneys taken from patients of both sexes, ranging from neonates to octogenarians, who had come to post mortem for one reason or another. Almost half of the first volume deals with examination of the urine and blood, accompanied by tables on the composition of urine relating water content to solids and the measurement of its specific gravity in a variety of ailments at different times of the day and night. Later pages are devoted to what Rayer calls "simple nephritis" - rather inappropriately, as the cases described represent renal changes that are secondary to a vast assortment of insults to the kidney, including trauma, obstruction, infection and other systemic diseases that would not now be classified as glomerular nephritis. This group is illustrated by case histories, or "observations" as they were called, of 102 patients, the majority of whom underwent post mortems. The Paris school led the field in the use of the microscope in medicine at that time and six plates at the end of this volume show the microscopic appearance of cellular, crystalloid and amorphous urinary sediment, including spermatozoa.

Volume 2 contains 99 "observations", largely from patients with acute and chronic albuminous nephritis or "maladie de Bright". It is the translation of Rayer's history of this condition from volume 2 that appears in the present book. It concludes with two tables, one recording the results of the screening for albuminuria of 71 children routinely admitted to the acute ward of the children's hospital, and the other reporting on the specific gravity of blood obtained from therapeutic venesection in adult patients suffering from a variety of different pathologies.

Volume 3 provides a further 151 "observations" on a very wide range of renal conditions, such as cancer, tuberculosis, calculi, cysts and hydronephrosis. It also includes a section that encompasses diseases of the ureter, bladder and prostate, and other subjects as diverse as renal complications of pregnancy and the history of nephrotomy. Each volume concludes with a table of contents (see Appendix 1).

This three-volume magnum opus contains within its 2,000 plus pages more than 350 case histories with supporting references for each subject. The accompanying atlas of 60 plates, drawn mainly by Ambroise Tardieu, a physician colleague of Rayer, illustrates the post-mortem appearances of many of the conditions discussed in the books. Equally important are the extensive accompanying references and footnotes to the text, and the bibliography, which supplies a rich vein of references for all topics discussed. However, the work's greatest merit, and what makes it outstandingly unique, is the inclusion of historical sections supplementing the main topics such as albuminous nephritis. Medical historians studying the evolution of our understanding of the kidney, its appendages and diseases up to the middle of the nineteenth century need look no further: Rayer's work is of enormous importance and value. Very few early or contemporary studies of the kidney in whatever language escape his attention, a fact that appears all the more remarkable in an age when communications were limited. Like Bright, he must have been an accomplished linguist as he translated books and journals from English, German, Italian, Spanish and classical Latin. However, he did leave large sections in the original Latin-the medical language of the time. Interestingly, Bright paid scant attention to either past or contemporary work on the kidney, apart from a few brief references to work such as that of John Blackall (1771-1860). Rayer, therefore, was not only a formidable medical historian, but also the first to tackle exclusively the history of renal medicine. It is worth looking a little 


\section{Introduction}

closer at how remarkably early the interest in medical history and bibliography developed, and how it evolved down the centuries.

The study of medical history, which is so intimately related to medical bibliography and biography, was not a new discipline in the nineteenth century when Rayer was working on his text. Aurelius Cornelius Celsus, who lived in the time of Tiberius Caesar (AD 14-37), is generally regarded as the first medical historian. His elegant classical Latin writing in De re medica, in which he records the work of seventy-two previous medical writers, including Hippocrates and Erasistratus, earned him the title of the medical Cicero. The next most important contribution comes from the pen of Guy de Chauliac (1300-68), a physician-surgeon who practised in Avignon and became physician and commensal chaplain to the Papal court. He was a learned writer with a strong historical interest and his Capitulum singulare on the history of medicine provided the only work of consequence between Celsus and his French compatriot Symphorien Champier of Lyons (1471-1535). Champier was physician to the Royal Court and one of the earliest French humanists and he wrote not only the best textbook of that era on the subject but also one of the best medical dictionaries. He was the first to recognize the importance of Chauliac's work.

The study of medical history seems to have held an important place in French medical circles from the Middle Ages and the Renaissance onwards, and to some extent the tradition extended to other European countries. Conrad Gesner (1516-65) of Zürich included all known medical writers in his Bibliotheca universalis (1545-59), and although the work remained incomplete it nevertheless provided the best pre-Hallerian record of medical bibliography. According to F. H. Garrison in his Introduction to the history of medicine, the earliest major work dedicated to the history of medicine, by Daniel Leclerc (1652-1728), was published in 1696. This appeared in French as Histoire de la médecine in 1702. The end of the seventeenth century heralded the age of medical dictionaries, which often contained valuable medical biographies. Garrison also attributed the earliest German history of medicine, published in 1728, to Johann Heinrich Eder (1687-1744).

By the eighteenth century the study of medical history was well established. Albrecht von Haller (1708-77) is generally accepted as the principal founder of medical and scientific bibliography. A graduate of Leyden, where he was trained by Hermann Boerhaave, von Haller was a prolific writer; in his lifetime he completed an astonishing 1,300 scientific articles. He was considered to be the most accomplished medical historian since Guy de Chauliac. In addition to Haller, several other authors contributed works on medical history at that time and one of the most interesting was John Freind (1675-1728). An Oxford graduate from Croton in Northamptonshire, he wrote The history of physick; from the time of Galen to the beginning of the sixteenth century while imprisoned in the Tower for treason following the Earl of Peterborough's Spanish campaign when he was medical officer to the English forces (1725-26). This work was intended to be a sequel to Leclerc's earlier publication.

Without doubt, however, the most accomplished medical historian of the nineteenth century, and a contemporary of Rayer's, was the Pomeranian botanist Kurt Polycarp Sprengel (1766-1833) whose book Versuch einer pragmatischen Geschichte der Arzneikunde was published at the beginning of the century and later translated into French and Italian. This may well have been a source for some of Rayer's historical sections and footnotes, possibly augmented by the works of Thomas Young (1813) and John Bostock 


\section{The History of Albuminous Nephritis}

(1835) as the latter may well also have contained much useful renal material. However, the most comprehensive account of the medical literature of the last half of the eighteenth century and the first half of the nineteenth century was the Medicinisches SchriftstelleLexicon, published in 33 volumes between 1830 and 1845 by the Danish surgeon Adolph Carl Peter Callisen (1787-1866). He is ranked alongside Haller as one of the greatest medical historians of all time and his work was the precursor of today's Index Medicus. Rayer, in the established French tradition, had a strong historical conscience and a highly developed interest in medical history: he and his colleague Gabriel Andral (1797-1876) encouraged their friend Émile Littré (1801-81), one of France's greatest medical writers, to prepare a bilingual edition of Hippocrates' works.

It is notable that Henry Sigerist (1891-1957) felt that a definitive medical history could not exist, as views and interpretations were subject to continuous change or refinement. Most medical historians recognize the continuous debates regarding "first descriptions", erroneous eponymous titles and modern interpretations of old treatises. There is no doubt that in the third part of Néphrite albumineuse, as he struggles to clarify the problems surrounding albuminous nephritis, Rayer comes up against the tenet of this homily. The discoveries of the middle fifty years of the nineteenth century were rapid, unprecedented and momentous, with physiological, pathological, microscopical, biochemical and clinical disciplines expanding rapidly and commensurately. Rayer and his contemporaries could not be aware of the myriad presentations of glomerular nephritis that we recognize today, as we shall see in the later commentary on the text.

By the beginning of the nineteenth century, the medical profession was entering a period of logical thought, the minds of the more radical and liberal doctors uncluttered by the preceding years of untenable dogma, whether theological or metaphysical. Garrison called it "the beginning of organized advancement in medicine". The sthenic/asthenic Brunonian theory of disease, and others of that ilk based mainly on whether the body was stimulated or relaxed, was supplanted by the Cartesian approach, where the body was seen as being similar to a machine, where organs had specific functions and tissues had dedicated roles. This was further established by the publication of Carl Ludwig's (1816-95) thesis of 1842 known as the "mechanistic paradigm" and by the earlier work of Marie-François Xavier Bichat (1771-1802) on membranes.

Therapy was also undergoing a "sea change". A bloodless revolution had taken place as, gradually, fewer patients were being subjected to dangerous depletion regimes based largely on purging and bloodletting, treatments that in many instances must have contributed to an early demise. Good clinical practice at the bedside, based on observation, examination and measurement, supplemented by chemical analysis of body fluids and, in the case of the kidney, improved urinalysis with post-mortem examinations where possible, had led to rapid developments in the understanding of disease processes. This was never more true than in the story that was to unfold regarding the association between albuminous urine, dropsy and abnormal changes in the kidney. The works of William Wells of St. Thomas's Hospital and John Blackall of Exeter in 1812 and 1813 respectively, had reported this association and had paved the way for Bright's seminal work of 1827 on renal disease, although without entirely pre-empting it. As Rayer so wisely indicates, Bright's "wonderful discovery was the natural fruit of the past and the conclusions drawn by a sagacious mind from his own observations and foregoing research" (see p. 14). 


\section{Introduction}

At this stage the medical world really started to look more assiduously at the several knotty problems surrounding what had come to be known as "Bright's disease". In the study of albuminous nephritis Bright had seen the importance of drawing the pathological kidneys that he had found at post mortem (he claimed to have sketched his first kidney in 1813). The lack of a "lingua franca" that would allow comparisons of pathological likenesses to be made between fellow workers at different centres was the main problem; no common nephrological language existed at the time. Where words would perhaps have failed to describe these lesions with any degree of consistency, the imagery of illustrated colour plates provided a set of standards for comparison by other observers: it was a classic case of a picture being worth a thousand words.

Although the use of drawing in medicine had reached a peak with Leonardo da Vinci the art had to be relearned and reapplied in the nineteenth century. It is interesting that the drawings of the kidneys are strikingly similar in the works of both Bright and Rayer, although it is generally considered that Bright's sketches, engraved by William Say in the plates of volume 1 of Medical cases, are of greater technical and artistic merit than those in Rayer's atlas. However, this does not apply to the later engravings by Oudet, which are of considerable elegance and accuracy, particularly those depicting renal stones. One cannot over-emphasize the impact of accurate illustrations delineating different pathological lesions. It is not, I believe, too outrageous to suggest that it was by drawing the kidney in dropsy that Bright won the eponymous accolade for his studies, so nearly pre-empted by the work of Wells and Blackall some years earlier. Rayer also appreciated the importance of being visually articulate and the atlas illustrating his treatise on renal disease must stand alongside the great medical artistic works of the age.

Interestingly, both Bright and Rayer had held posts in departments of dermatology where illustrative techniques flourished. It is likely that the importance of painting the picture of diseases, as recommended by Philippe Pinel (1745-1826), had been further reinforced during Rayer's attachment to the skin department, where he compiled his equally magnificent atlas of skin diseases. The department was formerly directed by Jean-Louis Alibert (1768-1837), who was described by Sabouraud as "Un visual et un artiste" and who prided himself on using the painter's palette and the burin to represent his findings. This obviously had a strong influence on Rayer's approach to his work. Atlases seem to have proliferated in the first half of the nineteenth century, most notably those of Jules Germain Cloquet (1790-1883) on anatomy and Jean Cruveilhier (1791-1874), professor of pathology to the Paris faculty, on morbid anatomy.

In this, the first English translation of Rayer's history of albuminous nephritis, we have attempted to retain the flavour of the language of the period and have not, therefore, used terminology of the twentieth century; the intention has been to present the scene as it was in Rayer's time. The Latin passages in the text have also been translated into English. We have included a commentary to help the reader to understand some of the confusing and ambiguous nineteenth-century terminology and the enormous problems that beset these early pioneering renal physicians in their search for the truth about nephritis.

Rayer's "tour de force" the Traité des maladies des reins alone must award him pride of place as one of the foremost and greatest physicians to have adorned the renal specialty, dwarfing in many ways the achievements of his renowned colleague, friend 
The History of Albuminous Nephritis

and inspiration, Richard Bright. However, in retrospect, it may well be his journey back into the labyrinths of medical history that is considered of paramount importance. Rayer stated in the preface to volume 1 that "the first ambition of a doctor, should it not be to serve science and its practice?" There is no doubt of his abundant success in fulfilling this ambition. 